\title{
Silicalite-1 zeolite membranes on unmodified and modified surfaces of ceramic supports: A comparative study
}

\author{
M K NASKAR*, D KUNDU and M CHATTERJEE \\ Sol-Gel Division, Central Glass and Ceramic Research Institute (Council of Scientific and Industrial Research), \\ Kolkata 700 032, India
}

MS received 3 September 2008

\begin{abstract}
Silicalite-1 zeolite membranes were prepared hydrothermally on the porous ceramic supports, both unmodified and modified with 3-aminopropyl triethoxysilane (APTES) as a coupling agent following ex situ (secondary) crystal growth process. The microstructure of the membranes was examined by scanning electron microscopy (SEM). The permeation study with a single gas, nitrogen $\left(\mathrm{N}_{2}\right)$ was performed through the membranes. For the surface modified support, a more surface coverage of the seed crystals on the porous support was observed resulting in a relatively higher dense packing of the crystals during secondary crystal growth process compared to that obtained from the unmodified support. The membrane developed on surface modified support rendered lower permeance value i.e. $9 \times 10^{-7} \mathrm{~mol} \mathrm{~m}^{-2} \mathrm{~s}^{-1} \mathrm{~Pa}^{-1}$ of $\mathrm{N}_{2}$ compared to that formed on the unmodified support which gave permeance value of $20 \times 10^{-7} \mathrm{~mol} \mathrm{~m}^{-2} \mathrm{~s}^{-1} \mathrm{~Pa}^{-1}$ of $\mathrm{N}_{2}$.
\end{abstract}

Keywords. Silicalite-1 membranes; surface modification; secondary growth; X-ray diffraction (XRD); scanning electron microscopy (SEM); gas permeation.

\section{Introduction}

Zeolites, the inorganic crystalline materials have drawn increasing attention in recent years because of their welldefined crystalline structures with uniform micropores. Zeolites grown as thin films on porous support are becoming an intense research interest because of their potential applications as gas or liquid separation membranes (Lai et al 2003), catalytic films (Masuda et al 2003), chemical sensors (Bein 1996), corrosion resistant coatings (Cheng et al 2001) and dielectric thin films (Wang et al 2001). For many applications, zeolite thin films (membranes) are becoming important because of their high thermal, chemical and mechanical stabilities. A number of zeolite membranes such as MFI (Vroon et al 1998), LTA-type (Xu et al 2000), FAU-type (Kusakabe et al 1997), DDRtype (Tomita et al 2004) were prepared on different types of supports. Many methods have been developed for preparing zeolite membranes, including in situ hydrothermal crystallization (Jia et al 1993), seed-growth or secondary (ex situ) crystallization (Hedlund et al 1999), spin coating of colloidal zeolite crystals (Mintova and Bein 2001), vapour-transport method (Kikuchi et al 1997) and electrophoretic technique (Huang and Yang 2007) etc.

It has been demonstrated that the performance of zeolite films can be improved by proper crystal orientation (Davis 2003; Li et al 2004) of zeolite crystals in the film.

*Author for correspondence (milan@cgcri.res.in)
It has been reported that the formation of mesoporous silica intermediate layers on the substrate optimizes the orientation and morphology of MFI membranes (Lai et al 2004; Mabande et al 2005). For obtaining high coverage, orientation and proper anchoring of the zeolite seed crystals on the support surface, silane coupling agents have been used (Ha et al 2000; Lee et al 2006; Yang et al 2007)

In the present investigation, silicalite-1 films (membranes) were developed hydrothermally on the porous ceramic supports, both unmodified and modified with 3-aminopropyl triethoxysilane (APTES) as a coupling agent following ex situ (secondary) crystal growth processes. A comparative study was performed with the above membranes through their microstructural examination and $\mathrm{N}_{2}$ permeation behaviours.

\section{Experimental}

\subsection{Preparation of silicalite-1 seed crystals}

Silicalite-1 seed crystals were prepared by hydrothermal synthesis of precursor solutions with the molar composition of 3TPAOH : 10TEOS : $1500 \mathrm{H}_{2} \mathrm{O}: 40 \mathrm{C}_{2} \mathrm{H}_{5} \mathrm{OH}$, where $\mathrm{TPAOH}$ is tetrapropylammonium hydroxide (Aldrich, USA, 1.0 M solution in water), TEOS is tetraethyl orthosilicate (Fluka, Switzerland, $\geq 98 \%$ ). In a typical synthesis, $4 \mathrm{~g}$ of ethyl alcohol $\left(\mathrm{C}_{2} \mathrm{H}_{5} \mathrm{OH}\right)$ (Bengal Chemical and Pharmaceutical Ltd., India, dehydrated) in $60 \mathrm{~g}$ of deioni- 
zed water was added to $4.6 \mathrm{~g}$ of TEOS under stirring followed by dropwise addition of $6.6 \mathrm{~g}$ of 1.0 (M) $\mathrm{TPAOH}$ to it. The stirring was continued for $1 \mathrm{~h}$ to form a clear solution. The clear precursor solution was then placed in a sealed Teflon-lined stainless steel autoclave and was kept in an oven preheated at $130^{\circ} \mathrm{C}$. The hydrothermal reaction was continued for $5 \mathrm{~h}$ followed by natural cooling at room temperature $\left(30^{\circ} \mathrm{C}\right)$. The seed crystals thus formed were collected by washing with deionized water followed by centrifugation for 3-4 times.

\subsection{Surface modification of support substrate}

Porous ceramics $\left(\alpha-\mathrm{Al}_{2} \mathrm{O}_{3}\right.$ and rutile based) disks of diameter $47 \mathrm{~mm}$ and thickness $2.5 \mathrm{~mm}$, supplied by Sterlitek Co. (Kent, WA 98032-1911, USA), was used as support for the preparation of silicalite-1 zeolite membranes. The support was cut into small disks of diameter $22 \mathrm{~mm}$ and cleaned with acetone in ultrasonic cleaner for $10 \mathrm{~min}$ followed by drying in air at $100^{\circ} \mathrm{C}$ for $6 \mathrm{~h}$.

The dry ceramic support was immersed in an ethanolic solution $(30 \mathrm{ml})$ containing $1.88 \mathrm{vol} \%$ of 3 -aminopropyl triethoxysilane (APTES) (Aldrich, USA, 99\%) in a sealed autoclave and heated at $100^{\circ} \mathrm{C}$ for $4 \mathrm{~h}$ (Yang et al 2007). The support substrate grafted with APTES was then washed with ethanol for 2-3 times.

\subsection{Deposition of seed crystals on unmodified and modified substrates}

A dispersion containing $0.06 \mathrm{wt} \%$ of silicalite- 1 seed crystals in ethanol was prepared under ultrasonication for $30 \mathrm{~min}$. The dispersion was divided into two parts and they were placed in two autoclaves. Both the substrates, unmodified and modified with APTES prepared as above, were immersed separately into the above dispersion by hanging through a Teflon thread attached from a Teflon rod fitted at the top of the autoclave bomb each. The sealed autoclaves were then kept in a preheated oven at $100^{\circ} \mathrm{C}$ for $4 \mathrm{~h}$ each. The seed coated supports were then rinsed with ethyl alcohol followed by baking at $250^{\circ} \mathrm{C}$ for $12 \mathrm{~h}$ at a heating rate of $1^{\circ} \mathrm{C} / \mathrm{min}$.

\subsection{Secondary growth of silicalite-1 film on modified and unmodified support substrates}

The modified and unmodified support substrates, coated with seed crystals in both the substrates, were immersed separately into the precursor solution of $3 \mathrm{TPAOH}$ : 10TEOS : $1500 \mathrm{H}_{2} \mathrm{O}: 40 \mathrm{C}_{2} \mathrm{H}_{5} \mathrm{OH}$ each, by hanging them through a Teflon thread as mentioned in $\$ 2.3$. The clear solutions with the support substrates were placed separately in two sealed autoclaves and kept in an oven preheated at $130^{\circ} \mathrm{C}$ for $30 \mathrm{~h}$ for secondary growth of silicalite-1 films onto the supports. They were rinsed with deionized water followed by calcinations at $450^{\circ} \mathrm{C}$ for $12 \mathrm{~h}$ with a heating rate of $1^{\circ} \mathrm{C} / \mathrm{min}$.

\subsection{Characterization of silicalite-1 seed crystals and membranes}

The silicalite- 1 seed crystals were characterized by X-ray diffraction (XRD) (Philips Corporation, Almelo, The Netherlands) with Ni-filtered $\mathrm{CuK}_{\alpha}$ radiation, Fourier transform infrared (FTIR) spectroscopy (Nicolet 5PC, Nicolet Analytical Instruments, WI) and scanning electron microscopy (SEM) (S 430i, LEO Electronic Microscopy Ltd., UK). The silicalite-1 films grown on the modified and unmodified support surfaces were characterized by SEM study. The permeation experiments were carried out by placing the prepared membranes in a stainless steel module with silicone O-rings. The single gas permeation of $\mathrm{N}_{2}$ was measured at room temperature $\left(30^{\circ} \mathrm{C}\right)$ with a transmembrane pressure, $\Delta P=1.5$ bar.

\section{Results and discussion}

Figure 1 depicts the XRD pattern revealing characteristic peaks of silicalite-1 prepared hydrothermally with the molar composition of 3TPAOH : 10TEOS : $1500 \mathrm{H}_{2} \mathrm{O}: 40$ $\mathrm{C}_{2} \mathrm{H}_{5} \mathrm{OH}$ at $130^{\circ} \mathrm{C}$ for $5 \mathrm{~h}$. The FTIR spectra of the asprepared silicalite-1 seed particles are shown in figure 2 . The characteristic absorption bands of silicalite-1 indicated at around $550 \mathrm{~cm}^{-1}$ (Ravishankar 1998) along with the appearance of doublet at $560 \mathrm{~cm}^{-1}$ and $540 \mathrm{~cm}^{-1}$. The morphology of the silicalite-1 seed crystals prepared hydrothermally with the above molar composition at $130^{\circ} \mathrm{C}$ for $5 \mathrm{~h}$ is shown in figure 3 .

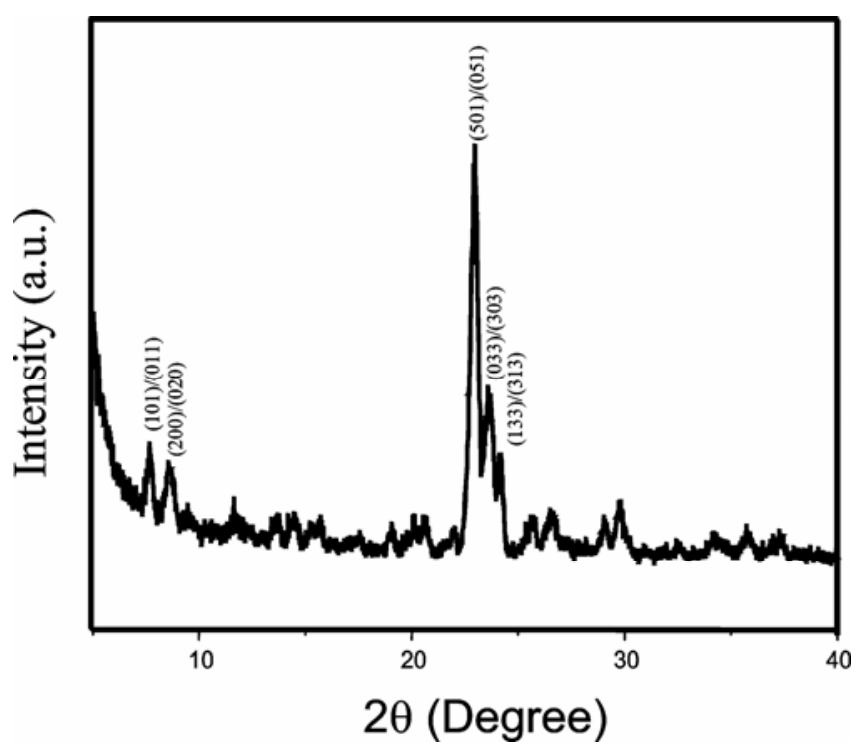

Figure 1. XRD pattern of silicalite-1 seed crystals prepared hydrothermally at $130^{\circ} \mathrm{C}$ for $5 \mathrm{~h}$. 
Figure 4 shows schematically the experimental steps along with proposed mechanistic route for the formation of silicalite-1 film on the modified porous ceramic substrate. In the first step, the porous ceramic surface was functionalized with APTES which can be attached to the ceramic surface through the amino $\left(-\mathrm{NH}_{2}\right)$ group (Yang et al 2007). Upon autoclave heating at $100^{\circ} \mathrm{C}$ for $4 \mathrm{~h}$, silicalite-1 seed crystals in ethanolic solution can interact with the surface functionalized ceramic substrate (second step). The silanol (-SiOH) group of seed crystal chemically attach with ethoxysilane $\left(-\mathrm{SiOC}_{2} \mathrm{H}_{5}\right)$ group of APTES forming $\mathrm{Si}-\mathrm{O}-\mathrm{Si}$ covalent linkages; it resulted in uniform

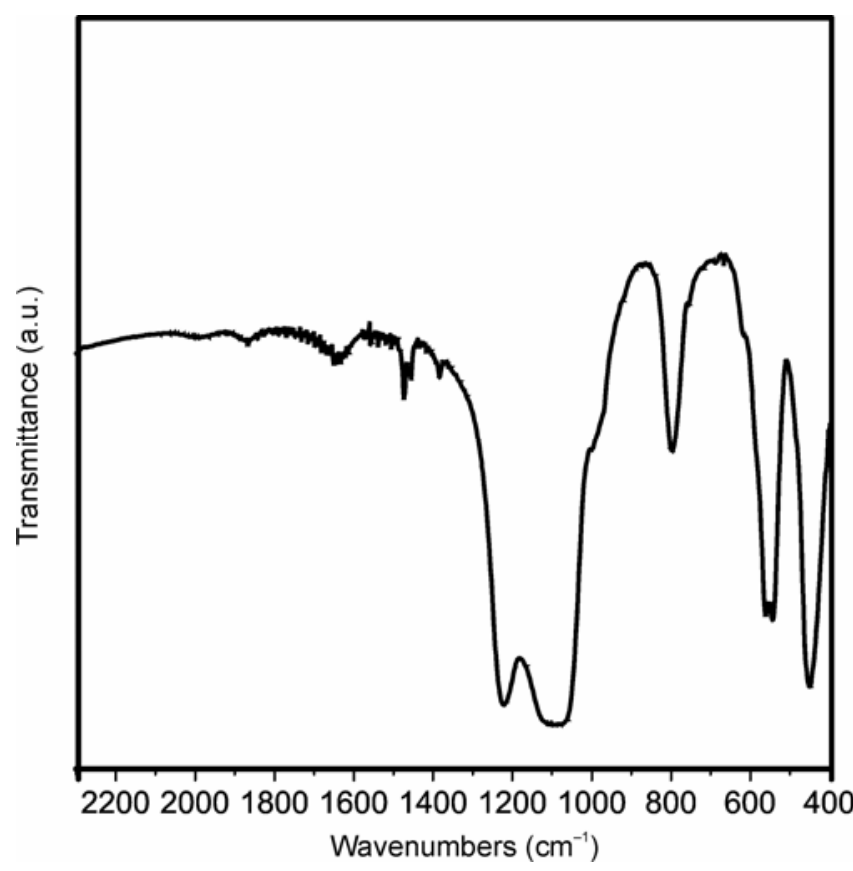

Figure 2. FTIR spectra of silicalite-1 seed crystals prepared hydrothermally at $130^{\circ} \mathrm{C}$ for $5 \mathrm{~h}$.

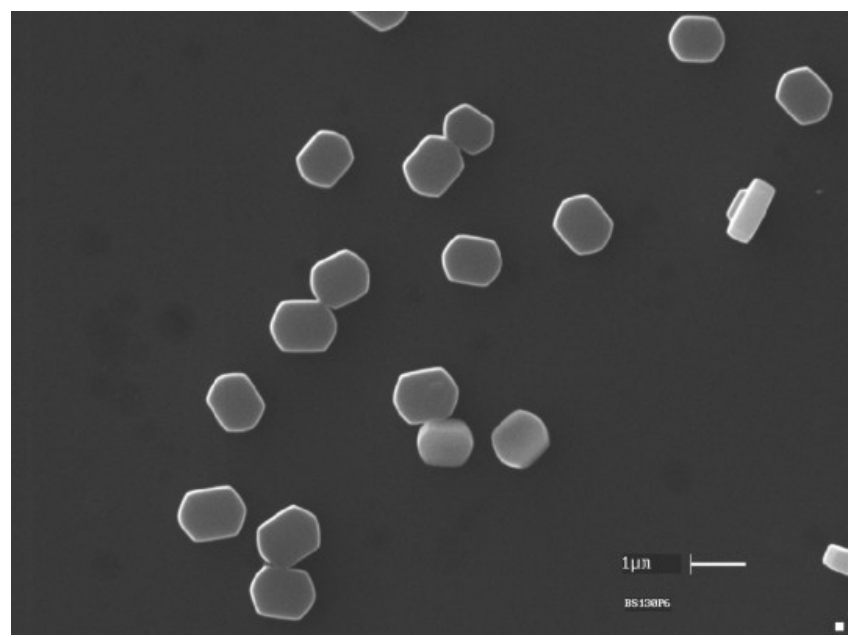

Figure 3. SEM image of silicalite-1 seed crystals prepared hydrothermally at $130^{\circ} \mathrm{C}$ for $5 \mathrm{~h}$ packing of the seed crystals onto the porous support surface. A secondary growth of silicalite-1, forming a thin film (third step) was observed after hydrothermal treatment of the surface modified porous support coated with the seed crystals in presence of precursor materials of silicalite-1.

SEM micrograph shows the assembly of silicalite-1 seed crystals on modified support surface (figure 5); the high magnification image of the above picture is shown in the inset of figure 5. Figure 6 indicates that less coverage of seed crystals on the unmodified support surfaces showing high magnification image in the inset. It is interesting to point out that surface functionalization of the support surface enhances well packing of the seed crystals on the surface compared to the same noticed on the

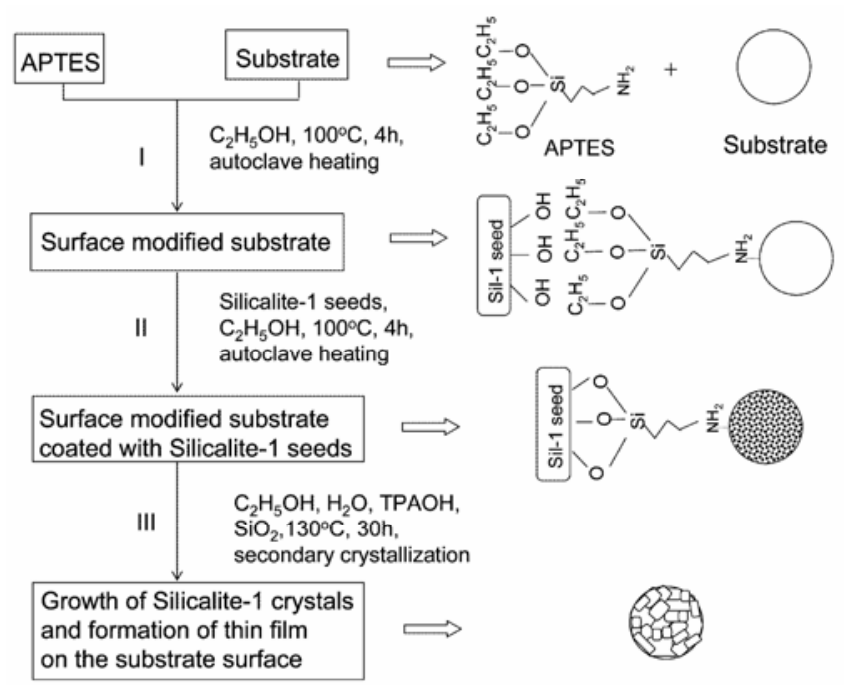

Figure 4. A schematic for the formation of silicalite-1 membrane (film) on porous ceramic substrate through surface modification technique.

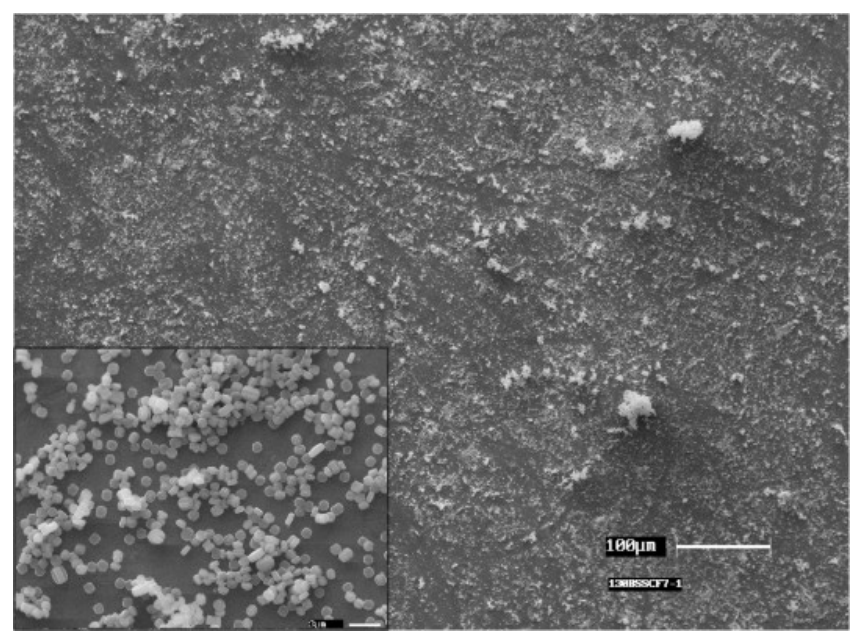

Figure 5. SEM image of silicalite-1 seed crystals deposited on surface modified support. 
unmodified substrate. It is to be noted that as the seed crystals covalently linked to the surface of the support through APTES linkers, the adhesion of seed layer became stronger compared to the deposition of seed crystals on the unmodified support surface. Figure 7 presents the SEM micrograph of silicalite-1 film grown by secondary crystallization (ex situ) on seed coated ceramic support modified with APTES while figure 8 shows the same on the unmodified support coated with silicalite-1 seed crystals. Secondary crystallization on surface modified substrate reveals better interlocking of the silicalite-1 crystals which can minimize the interzeolitic pores among the crystals (figure 7). However, some voids among the crystals were observed on the unmodified support, upon secondary crystallization (figure 8). More surface coverage of the seed particles on the modified substrate can generate well interlocking of the crystals during secondary crystallization.

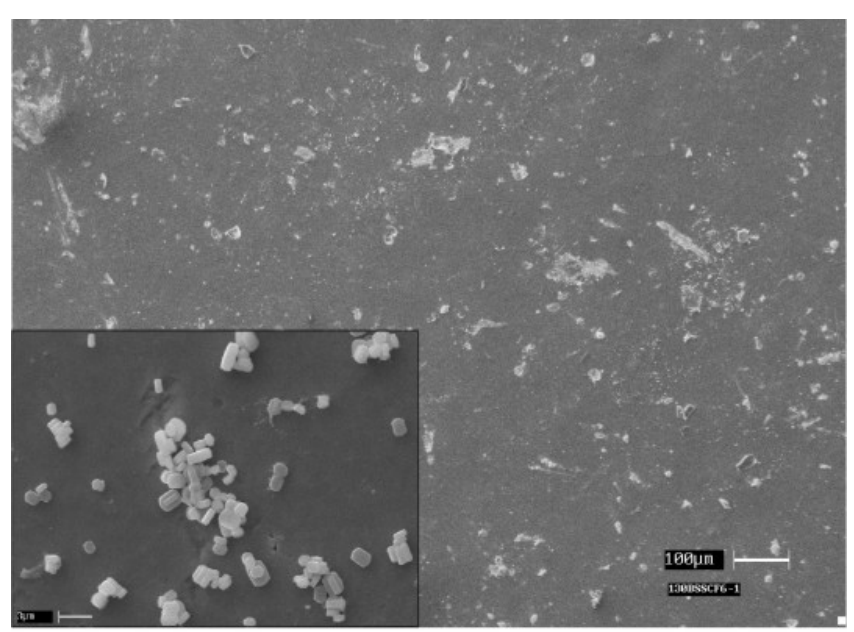

Figure 6. SEM image of silicalite-1 seed crystals deposited on unmodified support.

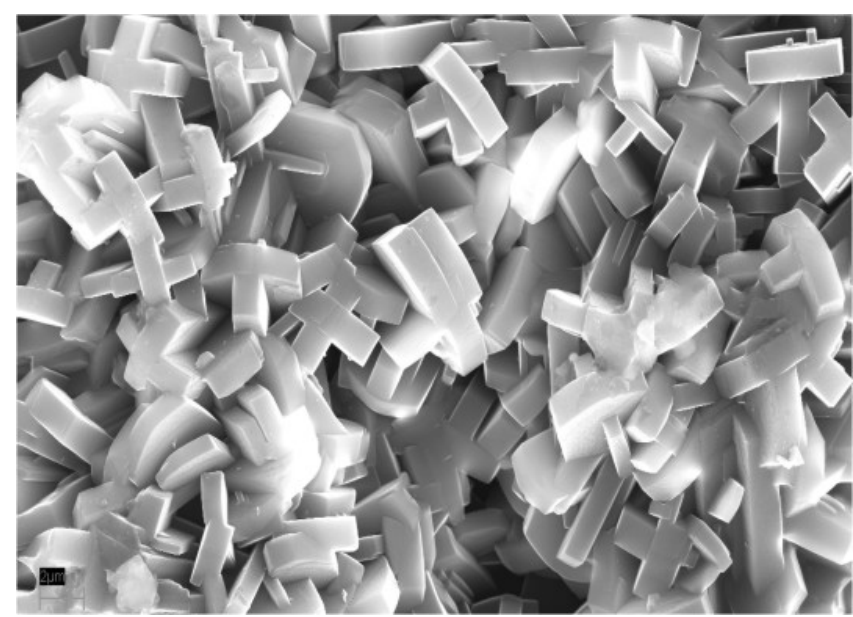

Figure 7. SEM image of silicalite-1 film grown by secondary crystallization (ex situ) on seed coated ceramic support modified with APTES.
Single gas permeance of $\mathrm{N}_{2}$ for the silicalite- 1 membrane prepared by surface modification technique was found to be at $9 \times 10^{-7} \mathrm{~mol} \mathrm{~m}^{-2} \mathrm{~s}^{-1} \mathrm{~Pa}^{-1}$ which is lower than that of literature value $\left(15.5 \times 10^{-7} \mathrm{~mol} \mathrm{~m}^{-2} \mathrm{~s}^{-1} \mathrm{~Pa}^{-1}\right)$ (Algieri et al 2003). However, a higher value i.e. $20 \times 10^{-7}$ mol m$~_{-2}^{-1} \mathrm{~Pa}^{-1}$ of $\mathrm{N}_{2}$ permeance was found for the membrane prepared on the unmodified support surface. It indicates that the membrane prepared by surface modification technique has higher interlocking of the crystals and hence a lower degree of interzeolitic pores among the crystals compared to that prepared on unmodified support surface. The permeance values of single gas, $\mathrm{N}_{2}$ can be lowered after repeated secondary crystallizations of the same membranes to minimize the interzeolitic pores in a higher extent. However, with increasing film thickness through the repeated crystallizations, there is a possibility of generation of defects, like crack formation etc of the prepared membranes.

\section{Conclusions}

Silicalite-1 zeolite film (membrane) was grown hydrothermally via secondary crystallization on a porous ceramic support (substrate) through its surface modification with 3-aminopropyl triethoxysilane (APTES) which was used as coupling agent between the porous support and seed crystals deposited on the porous support. For a comparative study, the same silicalite-1 membrane was prepared on the unmodified support surface via secondary crystallization. A better interlocking of the silicalite-1 crystals was obtained in the film after secondary crystallization (ex situ) of the seed-coated support modified with APTES compared to that crystallized (ex situ) on unmodified support surface; the former renders the higher

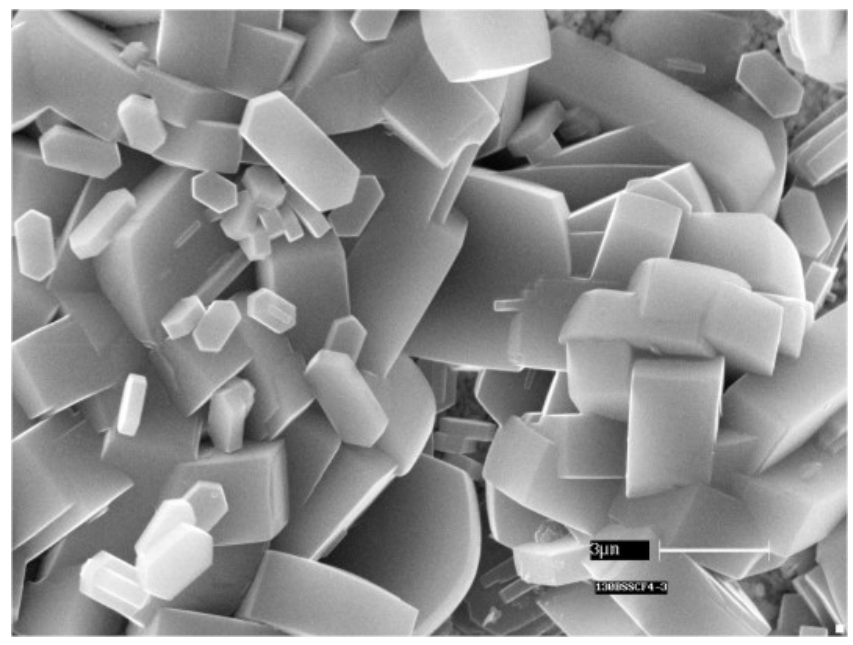

Figure 8. SEM image of silicalite-1 film grown by secondary crystallization (ex situ) on seed coated unmodified ceramic support. 
performance of silicalite-1 zeolite membrane in respect of single gas permeance of $\mathrm{N}_{2}$.

\section{Acknowledgements}

The authors sincerely thank Dr H S Maiti, Director, for his constant encouragement throughout the course of the work. They are thankful to the Council of Scientific and Industrial Research (CSIR), Government of India, for funding to carry out the above research work in the Project No. SIP 0023. They are also thankful to the colleagues of the X-ray Diffraction and SEM \& ESCA Sections of the Institute for characterization of the materials.

\section{References}

Algieri C, Bernardo P, Golemme G, Barbieri G and Drioli E 2003 J. Membr. Sci. 222181

Bein T 1996 Chem. Mater. 81636

Cheng X, Wang Z and Yan Y 2001 Electrochem. Solid-State Lett. 4 B23

Davis M E 2003 Science 300438

Ha K, Lee Y-J, Lee H J and Yoon K B 2000 Adv. Mater. 121114

Hedlund J, Mintova S and Sterte J 1999 Micropor. Mesopor. Mater. 28185
Huang A and Yang W 2007 Mater. Res. Bull. 42657

Jia M D, Peinemann K V and Behling R D 1993 J. Mem. Sci. 82 15

Kikuchi E, Yamashita K, Hiromoto S, Ueyama K and Matsukata M 1997 Micropor. Mater. 11107

Kusakabe K, Kuroda T, Murataka A and Morooka S 1997 Ind. Eng. Chem. Res. 36649

Lai Z et al 2003 Science $\mathbf{3 0 0} 456$

Lai Z, Tsapatsis M and Nicolich J P 2004 Adv. Funct. Mater. 14 716

Lee J S, Lim H, Ha K, Cheong H and Yoon K B 2006 Angew. Chem. Int. Ed. $\mathbf{4 5} 5288$

Li S, Wang X, Beving D, Chen Z and Yan Y $2004 \mathrm{~J}$. Am. Chem. Soc. 1264122

Mabande G T P, Ghosh S, Lai Z, Schwieger W and Tsapatsis M 2005 Ind. Eng. Chem. Res. 449086

Masuda T, Asanuma T, Shonji M, Mukai S R, Kawase M and Hashimoto K 2003 Chem. Eng. Sci. 58649

Mintova S and Bein T 2001 Adv. Mater. 131880

Ravishankar R 1998 J. Phys. Chem. B102 2633

Tomita T, Nakayama K and Sakai H 2004 Micropor. Mesopor. Mater. 6871

Vroon Z A E P, Keizer K, Burggraaf A J and Verweij H 1998 J. Mem. Sci. 14465

Wang Z, Wang H, Mitra H, Huang L and Yan Y $2001 A d v$. Mater. 13746

Xu X, Yang W, Liu J and Lin L 2000 Adv. Mater. 12195

Yang G, Zhang X, Liu S, Yeung K L and Wang J 2007 J. Phys. Chem. Solids 6826 